\title{
THE THORACIC SURGERY FOUNDATION FOR RESEARCH AND EDUCATION
}

\author{
Robert Wood Johnson Foundation Educational Opportunities
}

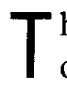
he Thoracic Surgery Foundation announces two opportunities for cardiothoracic surgeons to apply for educational experiences sponsored by the Robert Wood Johnson Foundation. There are indications of interest in having cardiothoracic surgeons apply for the Clinical Scholars Program and/or the Washington, DC-based Fellowships for Mid-Career Health Professionals.

1. The Robert Wood Johnson Clinical Scholars Program is designed to allow young physicians committed to clinical medicine to acquire new skills and training in the nonbiologic sciences important to medical care systems. The program offers 18 to 24 months of graduate level study and research as part of a university-based, postresidency training program. At least $20 \%$ of the Clinical Scholars' time is spent in relevant clinical activities as part of their experiences.

The Robert Wood Johnson Foundation has supported the Clinical Scholars program since 1973. Currently, seven institutions participate in the program and will be recruiting Scholars to begin the program in July 2000. These institutions are: the University of California, Los Angeles; the University of Chicago; the Johns Hopkins University; the University of Michigan; the University of North Carolina, Chapel Hill; the University of Washington, Seattle; and Yale University.

At each of these university sites, a study and research program is tailored to meet the Scholar's specific interests within the priority area the Scholar selects. Faculty and resources are available in a broad array of disciplines, including epidemiology, biostatistics, medical information sciences, economics, the social sciences, anthropology, history of medicine, law, ethics, and the humanities. Although the programs vary in design and emphasis, each has developed core programs to intro- duce Scholars to basic nonbiologic disciplines and methods used in health care research.

The Clinical Scholars Program will give cardiothoracic surgeons research tools that can be used over their entire careers.

2. Robert Wood Johnson Health Policy Fellowsmid-career health professionals from academic and community health settings nationwide--spend nearly a year in Washington, DC, learning first-hand how the health policy process works. Fellows have an extensive orientation, which brings them into contact with key policy leaders in the nation's capital and prepares them for their 9-month work assignments with members of Congress or the executive branch. In recent years, these assignments have covered the breadth of the political spectrum in health policy-including the offices of Senators Dole (Republican-Kansas), Rockefeller (Democrat-West Virginia), Hatch (Republican-Utah), Kassebaum (Republican-Kansas), and Kerrey (Democrat-Nebraska).

The Fellows consistently report that the program has had an enormous influence on their careers. Even when they do not work directly in policy afterward, they are much better able to help their colleagues and home institutions to understand the interplay of forces that are drastically changing our nation's health system. This is the pinnacle, introductory experience to how our political system works regarding health care.

Both programs are extraordinarily prestigious and will have continuing meaning for the careers of successful candidates. For further details and stipend information on these RWJ programs, contact The Thoracic Surgery Foundation office (phone: 312-644-6610; fax: 312-527-6635; e-mail: Frank_Kurtz@SBA.com). 